\title{
Middle Ear Adenoma
}

National Cancer Institute

\section{Source}

National Cancer Institute. Middle Ear Adenoma. NCI Thesaurus. Code C6834.

A benign, well-circumscribed glandular neoplasm that arises from the middle ear and may

exhibit neuroendocrine differentiation. It usually presents with conductive hearing loss. 